\title{
The chiton stripe tease
}

\author{
Julia D. Sigwart ${ }^{1,2}$
}

Received: 15 February 2016 / Revised: 1 October 2016 / Accepted: 2 October 2016 / Published online: 20 October 2016

(C) The Author(s) 2016. This article is published with open access at Springerlink.com

The chiton Tonicella lineata (Wood, 1815) is distinctive for its vivid colouration and striking patterns of colour blocks and stripes. The kaleidoscopic colours of this species is a familiar feature of the NE Pacific coastal fauna. Despite extensive study of the biology of Tonicella spp., their colour and patterns have never been the subject of rigorous investigation; thus, a few key preliminary observations are documented here. Shell colours in Tonicella spp. are anecdotally presumed to be derived from their primary diet of coralline algae (Piercy 1987), but this has not been tested chemically to date. Some pigments are evidentially unstable as the colours, particularly blue and pale pink, fade extremely rapidly in preserved specimens or around the site of shell breakage injuries in living animals (Fig. 1a, cf. image at upper right). Tonicella lineata range in shade from dark red, to pink, orange, purple or cyan blue, with an underlying pattern of divergent diagonal banding composed of these colours, faintly present even when the valve colour appears superficially solid (Fig. 1a, $c f$. image at the centre, which is solid blue). Consistent differences in patterning have been used as one feature of taxonomic separation of species within the genus (Clark 1999). But there is also finerlevel variation, and examination of photo datasets for T. lineata across its geographic range showed that these patterns are unique at the individual level, in the same way as other natural patterns, from snowflakes to zebras. Even

Communicated by V. Urgorri

Julia D. Sigwart

j.sigwart@qub.ac.uk

1 Marine Laboratory, Queen's University Belfast, 12-13 The Strand, Portaferry, Northern Ireland

2 Museum of Paleontology, University of California, Berkeley, 1101 VLSB, Berkeley, CA 94720, USA between specimens that have apparently similar ornamental patterns, close examination will find differences on at least one shell valve (Fig. 1a, cf. images in the lower row).
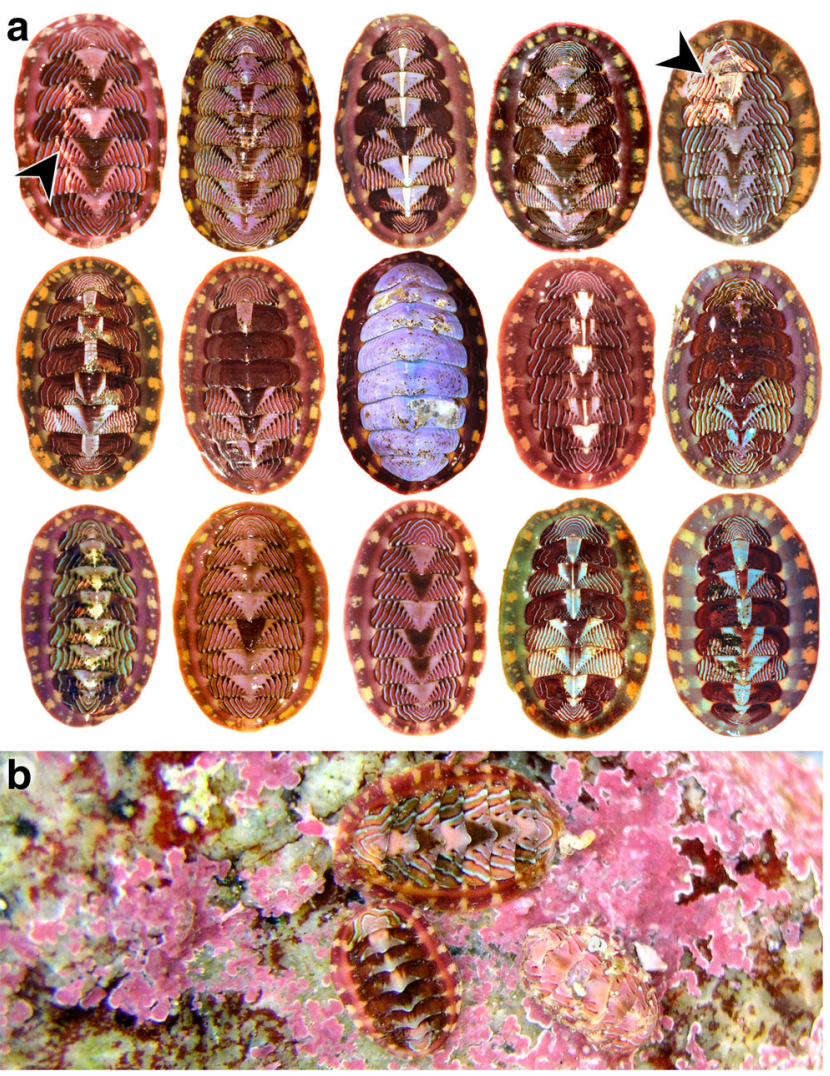

Fig. 1 Colour patterning in Tonicella lineata. a Individual variation among 15 live animals, showing shell colours without any encrusting epibiota. The arrowheads indicate areas of pigment bleaching in vivo around shell breakages. b Effective camouflage of three live animals on encrusting coralline algae. Animals collected and photographed in (a) Friday Harbor, San Juan Island, USA and (b) Bamfield, British Columbia, Canada 
Mathematical models of diffraction patterns describe the shell patterning in many molluscs (Field and Golubitsky 2009), but this has never been applied to the eight-shelled chiton armature. Combinations of striping and blocks on the shells and girdle of Tonicella may represent a 'maximum disruptive contrast' camouflage (Fig. 1b), which confounds edge detection mechanisms that are fundamental even in simple visual systems (Stevens and Cuthill 2006). This could be effective against likely chiton predators, including crabs and fish. Previous studies have noted the populationlevel advantage of colour polymorphisms camouflage in chitons (e.g. Goncalves Rodrigues and Silva Absalão 2005). The defensive stripes on each $T$. lineata represent a sophisticated visual defence in animals with no eyes themselves.

Acknowledgements Thanks go to Nick Carey (Hopkins Marine Station, Stanford University), Chong Chen (JAMSTEC) and Lindsey Dougherty (UC Berkeley) for their assistance with animal collection and photography. Dan Speiser and Suzanne Williams graciously provided constructive reviews of an earlier version of this article.
Open Access This article is distributed under the terms of the Creative Commons Attribution 4.0 International License (http:// creativecommons.org/licenses/by/4.0/), which permits unrestricted use, distribution, and reproduction in any medium, provided you give appropriate credit to the original author(s) and the source, provide a link to the Creative Commons license, and indicate if changes were made.

\section{References}

Clark RN (1999) The Tonicella lineata (Wood, 1815) species complex (Polyplacophora: Tonicellidae), with descriptions of two new species. Am Malacol Bull 15:33-46

Field M, Golubitsky M (2009) Symmetry in chaos: a search for pattern in mathematics, art, and nature. SIAM, Philadelphia

Goncalves Rodrigues LR, Silva Absalão R (2005) Shell colour polymorphism in the chiton Ischnochiton striolatus (Gray, 1828) (Mollusca: Polyplacophora) and habitat heterogeneity. Biol J Linn Soc 85:543-548

Piercy RD (1987) Habitat and food preferences in six Eastern Pacific chiton species (Mollusca: Polyplacophora). Veliger 29:388-393

Stevens M, Cuthill IC (2006) Disruptive coloration, crypsis and edge detection in early visual processing. Proc R Soc B Biol Sci 273(1598):2141-2147 